\title{
UNJUK KERJA APLIKASI DIGITAL SIGNAGE XIBO PADA PROSES PEMBUATAN PAPAN PENGUMUMAN DIGITAL DI JURUSAN TEKNIK ELEKTRO
}

\author{
Oleh \\ Ketut Udy Ariawan \\ Prodi D3 Teknik Elektronika, FTK, UNDIKSHA \\ udyariawan@gmail.com
}

\begin{abstract}
ABSTRAK
Selama ini Jurusan Teknik Elektro di Fakultas Teknik dan Kejuruan Universitas Pendidikan Ganesha telah memanfaatkan media website sebagai sarana penyampaian informasi. Namun dalam lingkungan internal jurusan masih juga menggunakan cara konvensional dengan menempel lembar pengumuman pada papan informasi yang tersedia. Di era digital, papan pengumuman bermigrasi dari bentuk konvensional ke bentuk digital, sehingga dikenal istilah digital signage. Bentuk digital signage yang sering diterapkan saat ini adalah menggunakan seperangkat komputer yang dihubungkan ke satu atau beberapa buah TV Plasma untuk menampilkan informasi. Salah satu aplikasi digital signage yang mendukung proses pembuatan papan pengumuman digital dan berbasis Web adalah XIBO yang bersifat open source.

Pada penelitian ini, proses pembuatan papan pengumuman digital dilakukan dengan cara membuat sebuah sistem yang terdiri dari komposisi software (XIBO, Web Hosting, dan Internet) dan hardware (PC Server, PC Client, dan TV Plasma). Aplikasi XIBO yang digunakan terdiri dari XIBO CMS untuk diinstallkan pada web hosting melalui PC Server, XIBO CLIENT FOR WINDOWS untuk diinstallkan pada PC Client agar bisa terhubung dengan PC Server, dan TV Plasma digunakan untuk menampilkan display hasil desain konten papan pengumuman digital yang telah dibuat agar terlihat lebih tajam, cerah, dan besar jika dibandingkan menggunakan monitor komputer biasa. Penerapan XIBO pada web hosting dimaksudkan agar proses pembuatan desain konten papan pengumuman digital dan jadwal tayangnya dapat dilakukan secara online, dimana saja, dan kapan saja oleh admin, sehingga hal ini akan menjadikan digital signage lebih efektif dan efisien dari segi waktu, tenaga, dan biaya serta mudah dalam hal pengoperasiannya. Hasil penelitian ini nantinya diharapkan dapat memberikan kontribusi pada sarana penyampaian informasi secara digital terutama dalam bidang periklanan/advertising.
\end{abstract}

Kata-kata kunci: Digital Signage, Web Hosting, XIBO.

\begin{abstract}
During this time the Department of Electrical Engineering at the Faculty of Technical and Vocational Ganesha University of Education has been using the media as a means of delivering information website. But in the internal environment department was also using the conventional way with an announcement on a board attached sheet available information. In the digital era, bulletin boards migrate from conventional forms to digital form, so that the technical term is digital signage. Forms of digital signage is often applied at this time is to use a computer that is connected to one or a few pieces of Plasma TVs to display the information. One digital signage applications that support the process of making digital bulletin boards and Web-based is Xibo that is open source.

In this research, the process of making a digital notice board is done by creating a system consisting of software composition (Xibo, Web Hosting, and Internet) and hardware (PC Server, PC Client, and Plasma TVs). Applications Xibo used consisted of
\end{abstract}


Xibo CMS for installed on web hosting through a PC Server, Xibo CLIENT FOR WINDOWS for installed on the PC Client to be connected to a PC server, and Plasma TV used to show display design results content announcement board digital has been made to look sharper, brighter, and large when compared to using a regular computer monitor. Application of Xibo web hosting is so that the process of making content design bulletin boards digital and schedule slot can be done online, anywhere and anytime by admin, so this will make the digital signage is more effective and efficient in terms of time, effort, and expense as well as easy in operation. Results of this research is expected to contribute to the means of delivering digital information, especially in the field of advertising.

Keywords: Digital Signage, Web Hosting, Xibo.

\section{PENDAHULUAN}

Saat ini sangat umum kita perhatikan suatu papan informasi yang ada di perkantoran, di gedung perkuliahan, di bandar udara maupun stasiun kereta api yang berupa suatu monitor layar datar yang dikendalikan oleh suatu komputer. Dari satu sisi hal ini lebih mudah dioperasikan daripada menggunakan metode lama menggunakan papan pengumuman konvensional ataupun papan penunjuk arah. Dengan menggunakan komputer, informasi bisa lebih dinamis dan media yang ditampilkan lebih beragam. Papan pengumuman digital berbasis komputer tersebut saat ini biasanya memanfaatkan komputer yang terhubung jaringan dan mampu untuk dikendalikan secara jarak jauh untuk mengatur apa yang akan ditampilkan.

Digital signage merupakan aplikasi pengelola konten digital yang telah diprogram untuk dapat menampilkan urutan informasi atau pesan kepada target penonton/audien secara efektif, cepat, tepat dan handal. Digital signage sangat memanjakan mata penonton/audien dalam memberikan tontonan visual yang menarik dan atraktif, beraneka pesan atau informasi berformat multimedia dapat dengan mulus dimainkan, diantaranya berupa gambar, video, scroll text, chart, grafik, schedule, news, weather yang disajikan secara dinamis menggunakan media display elektronik seperti LCD TV, TV Plasma, Proyektor, dan Digital Billboard sebagai output.

Saat ini digital signage menjadi trend media komunikasi digital di seluruh belahan dunia karena kemampuannya dalam mengolah informasi data yang handal dan mudah dalam pengoperasionalannya dari membuat materi, mendesain template, memanage resource, dan mengatur jadwal tayang. Bayangkan bila kita memiliki jaringan digital signage pada bisnis kita, seperti mini market, supermarket, hotel, bank, cellular provider, klinik dan lain sebagainya yang mempunyai cabang terletak di dalam dan luar kota, dan kita sebagai pemilik bisnis dapat mengontrol, memonitor, mengupdate dan memanage semua informasi yang ingin kita bagi kepada karyawan maupun konsumen, dan semua itu dapat langsung kita lakukan secara bersamaan ke seluruh cabang bisnis kita dimanapun 
secara online, real-time dan terpusat. Tentu hal ini akan sangat flexible, menghemat waktu serta biaya terutama untuk lebih meningkatkan pelayanan kepada konsumen.

Dengan semakin bertumbuhnya teknologi digital signage dan membuka peluang bisnis media iklan, maka tidak sedikit dari pengelola bisnis, seperti supermall dan supermarket memanfaatkan teknologi digital dengan memasang TV Plasma pada titiktitik strategis yang banyak dilihat pengunjung sebagai media komunikasi dan promosi sekaligus menjadi target market iklan. Tentu saja hal ini tidak lepas dari peran teknologi informasi yang memang menjadi core bisnis strategic, serta aplikasi pendukung digital signage yang memang harus dapat menangani kebutuhan untuk mengelola konten multimedia tersebut.

Dalam dunia pendidikan media penyampaian informasi sangat penting dilakukan. Selama ini di Jurusan Teknik Elektro, Fakultas Teknik dan Kejuruan, Universitas Pendidikan Ganesha proses penyampaian informasinya paling sering dilakukan dengan cara konvensional dengan menempelkan lembar pengumuman pada papan informasi ataupun melalui sarana website. Lembar pengumuman yang ditempelkan pada papan informasi tersebut tentu kurang menarik, kurang atraktif dan kurang dinamis bagi para pembacanya walaupun ditempatkan pada tempat yang strategis. Pengumuman yang juga disebarkan melalui sarana website jurusan hanya bisa dibaca oleh pembaca yang sedang online saja sehingga hal ini tentu saja masih dianggap kurang efektif dalam proses penyampaian informasi. Untuk itulah, sangat diperlukan suatu media penyampaian informasi digital di Jurusan Teknik Elektro yang bisa menarik minat penonton/audien untuk membaca atau memperhatikannya yang bersifat atraktif dan dinamis. Digital signage XIBO diharapkan bisa menjadi jawaban untuk mengatasi permasalahan tersebut yang tentunya bersifat lebih efektif dan efisien dari segi waktu, tenaga, dan biaya serta mudah dalam hal pengoperasiannya.

Penelitian yang membahas tentang penerapan digital signage XIBO pernah dilakukan oleh Vencysisca Jeane Risamena, Komang Isabella Anasthasia, dan Ni Made Ary Esta Dewi Wirastuti Jurusan Teknik Elektro, Fakultas Teknik, Universitas Udayana, "Penyisipan Konten Elektro News Menggunakan Xibo Digital Signage" menyimpulkan bahwa XIBO diimplemetasikan pada sebuah perangkat lunak XAMPP, yaitu sebuah software open source yang berfungsi sebagai server yang berdiri sendiri (localhost) dan display outputnya ditampilkan pada sebuah LCD monitor komputer biasa. 


\section{METODE PENELITIAN}

Pendekatan dalam penelitian ini menggunakan metode Penelitian dan Pengembangan (Research and Development/R\&D), sedangkan analisis yang digunakan adalah analisis S.M.A.R.T, yaitu Specific, Measurable, Achievable, Realistic dan Timebased. Perancangan penelitian meliputi perancangan hardware dan software. Selain itu dalam metode penelitian ini akan dibahas juga tentang lokasi penelitian, subjek dan objek (peubah yang diamati/diukur), teknik pengumpulan data, analisis data, dan luaran yang dijanjikan.

Menurut Borg and Gall (1989), ada empat ciri utama dalam R\&D, yaitu:

1. Studying research findings pertinent to the product to be developed. Artinya, melakukan studi atau penelitian awal untuk mencari temuan-temuan penelitian terkait dengan produk yang akan dikembangkan.

2. Developing the product based on this findings. Artinya, mengembangkan produk berdasarkan temuan penelitian tersebut.

3. Field testing it in the setting where it will be used eventually. Artinya, dilakukannya uji lapangan dalam seting atau situasi senyatanya dimana produk tersebut nantinya digunakan.

4. Revising it to correct the deficiencies found in the field-testing stage. Artinya, melakukan revisi untuk memperbaiki kelemahan-kelemahan yang ditemukan dalam tahap-tahap uji lapangan.

Dari empat ciri utama R\&D tersebut, memberikan gambaran bahwa ciri utamanya adalah adanya langkah-langkah penelitian awal tekait dengan produk yang akan dikembangkan. Berdasarkan hasil penelitian tersebut kemudian produk pendidikan dirancang dan dikembangkan untuk kemudian diuji dan diperbaiki atau direvisi.

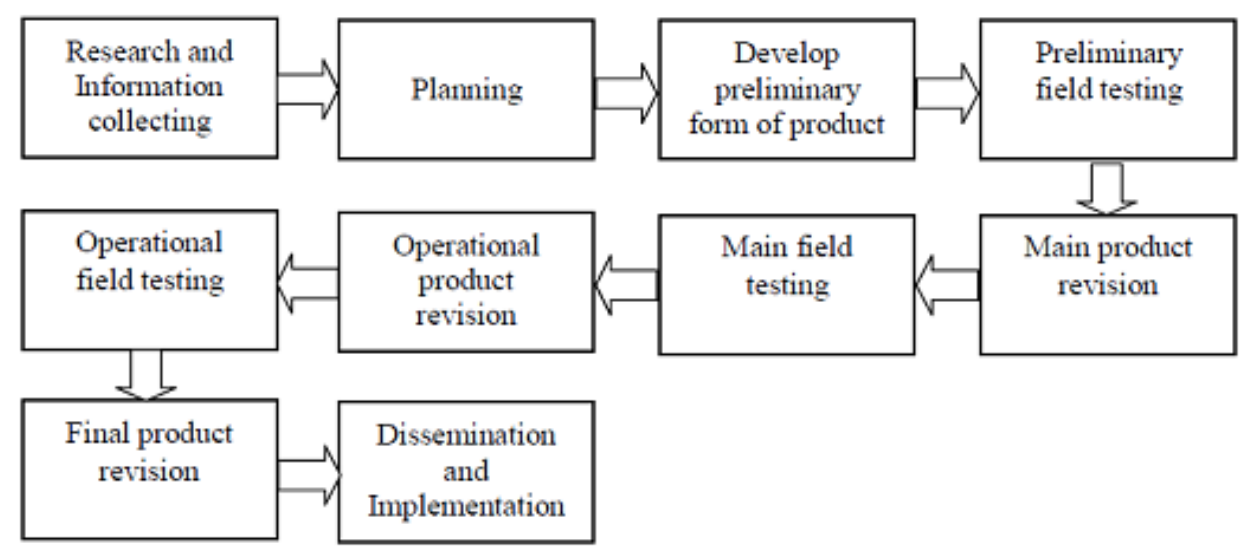

Gambar 1. Langkah-langkah Penggunaan Desain R\&D 


\section{Rancangan Penelitian}

\section{Perancangan Sistem Jaringan dan Software}

Proses pembuatan papan pengumuman digital ini akan menggunakan aplikasi digital signage XIBO yang terdiri dari XIBO CMS untuk diinstallkan pada sebuah web hosting melalui PC Server yang terhubung dengan internet dan XIBO CLIENT FOR WINDOWS untuk diinstallkan pada PC Client agar bisa terhubung dengan PC Server. Dari PC Client yang telah terkoneksi dengan PC Server, hasil desain konten papan pengumuman digital pada akhirnya akan ditampilkan pada display sebuah TV Plasma. Web hosting yang digunakan adalah web hosting untuk website Jurusan Teknik Elektro yang sudah ada dengan domain name (http://ee.undiksha.ac.id) dan sebagai tempat aplikasi XIBO diinstallkan, maka dibuatkan sebuah subdomain khusus (http://ee.undiksha.ac.id/digitalsignage). Koneksi internet yang digunakan adalah akses internet yang telah tersedia di kampus Undiksha yang menggunakan kabel UTP RJ45 untuk menghubungkan Router ke LAN Card pada PC Client agar kecepatan internet lebih stabil, sedangkan koneksi internet pada PC Server menggunakan akses internet Speedy dari TELKOM dengan kecepatan akses 1 Mbps yang dihubungkan dengan WiFi (internet tanpa kabel) agar lebih bersifat mobile sehingga proses pengeditan terhadap tampilan desain maupun isi konten papan pengumuman digital bisa dilakukan dimana saja dan kapan saja oleh admin.

TV Plasma yang digunakan memiliki ukuran layar 32 inch dan dihubungkan dengan PC Client melalui kabel VGA/HDMI untuk menampilkan display hasil desain konten papan pengumuman digital yang telah dibuat agar terlihat lebih tajam, cerah, dan besar jika dibandingkan menggunakan monitor komputer biasa.

\section{Perancangan Desain Konten}

Desain konten papan pengumuman digital dilakukan setelah XIBO CMS berhasil terinstall dan dilakukan konfigurasi pada web hosting melalui PC Server. Setelah masuk ke dalam menu XIBO CMS maka hal yang pertama dilakukan adalah mempersiapkan layout. Layout berfungsi untuk menentukan tema tampilan yang akan digunakan, setelah layout siap maka langkah selanjutnya adalah membuat region. Region berfungsi untuk menempatkan posisi gambar, video, dan running text pada layout dan bisa diubah-ubah ukurannya menyesuaikan dengan kebutuhan desain. Setelah desain konten siap, maka tahap selanjutnya adalah melakukan uji coba untuk menampilkan desain konten yang telah dibuat melalui tampilan website (preview layout) yang fasilitasnya terdapat di dalam menu XIBO CMS. Preview layout dilakukan dengan tujuan melihat sementara hasil 
desain konten sebelum ditampilkan pada display layar monitor PC Client yang terhubung dengan display TV Plasma.

\section{Perancangan Penjadwalan (Jadwal Tayang)}

Salah satu kemampuan yang ditawarkan oleh digital signage XIBO adalah tampilan hasil desain konten papan pengumuman digital yang bisa ditentukan jadwal tayangnya. Fasilitas ini terdapat di dalam menu XIBO, yaitu pada menu Schedule. Kemampuan penjadwalan digital signage XIBO ini dapat dimulai dari detik, menit, jam, hari, minggu, bulan dan tahun yang telah ditentukan dan dapat diakhiri pada waktu yang telah ditentukan dalam jangka waktu satu tahun. Adapun jadwal tayang papan pengumuman digital yang akan dibuat ini direncanakan agar bisa tampil pada hari-hari kerja dan jam kerja tertentu selama satu bulan, sehingga diluar waktu tersebut papan pengumuman digital yang dirancang ini tidak akan tampil.

\section{HASIL DAN PEMBAHASAN}

\section{a. Hasil Penelitian}

Pada proses pembuatan papan pengumuman digital ini dirancang sebuah skema jaringan seperti Gambar 2 berikut.

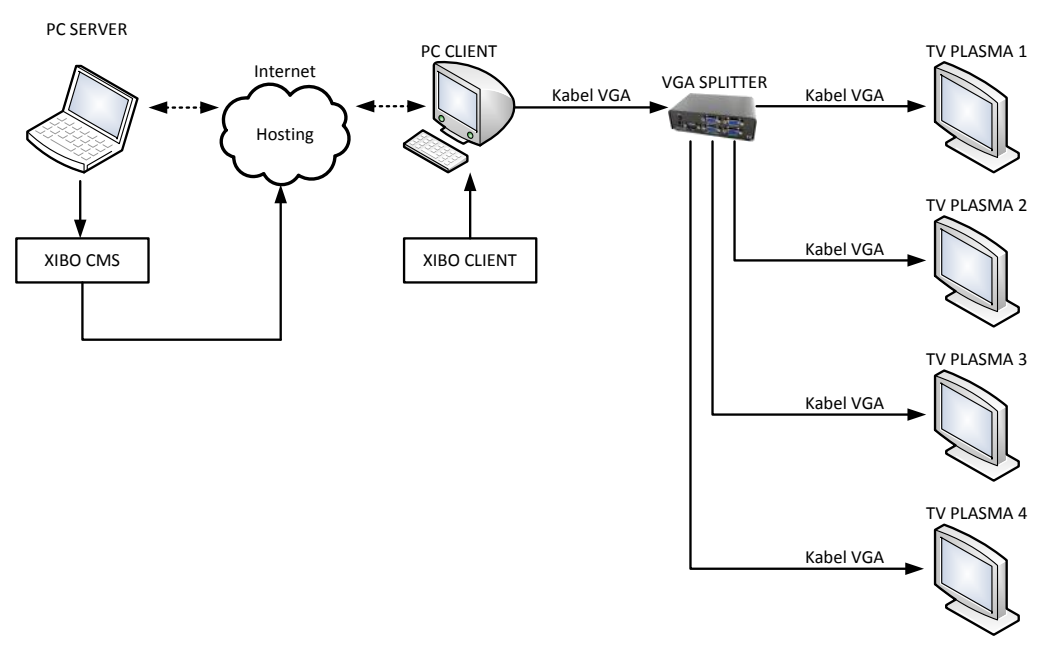

Gambar 2. Skema Pembuatan Papan Pengumuman Digital

\section{Proses Desain Layout di dalam XIBO CMS}

Penyisipan konten pada XIBO berkaitan erat dengan desain layout. Gambaran secara umum adalah ketika pengguna hendak memasukkan konten, pengguna harus menginputkan layout sesuai dengan desain yang telah ditetapkan sebelumnya, kemudian 
membentuk region (daerah-daerah kecil). Dalam satu desain dapat menggunakan lebih dari satu region, hal ini dapat disesuaikan dengan kebutuhan. Ketika region telah selesai dibuat, barulah konten disisipkan ke dalam masing-masing region. Pada proses pembuatan papan pengumuman digital ini menggunakan 9 region, seperti terlihat pada Gambar 3 berikut ini.

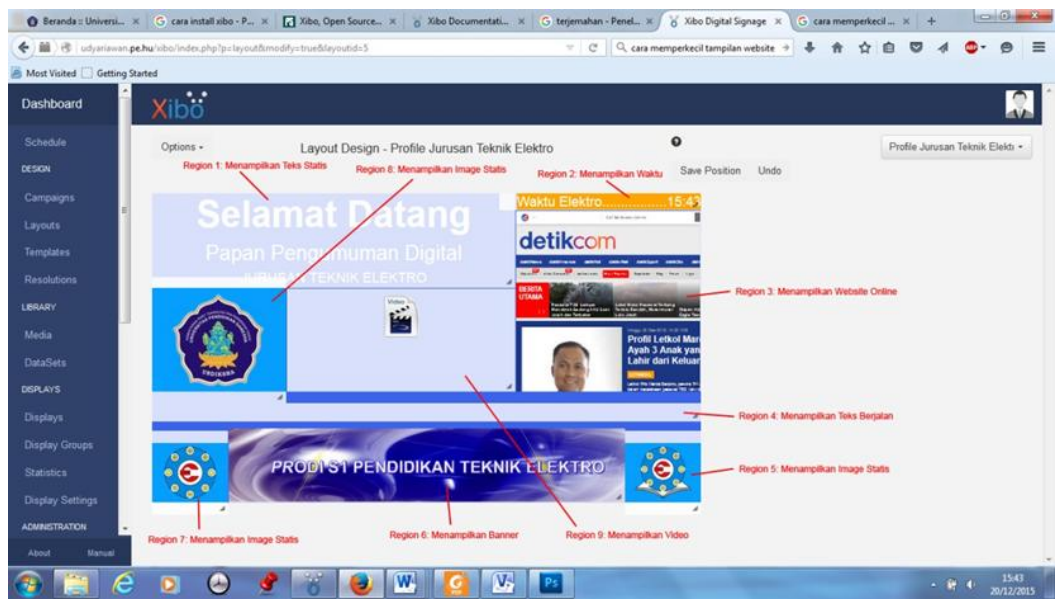

Gambar 3. Pembagian Region

- Region 1: Untuk menampilkan teks statis

- Region 2: Untuk menampilkan waktu

- Region 3: Untuk menampilkan homepage website secara online

- Region 4: Untuk teks berjalan dari kiri ke kanan

- Region 5: Untuk menampilkan image/gambar statis

- Region 6: Untuk menampilkan banner dinamis

- Region 7: Untuk menampilkan image/gambar statis

- Region 8: Untuk menampilkan image/gambar statis

- Region 9: Untuk menampilkan video

Proses pembuatan desain layout dan region dapat dibaca langsung pada website resmi XIBO (www.xibo.org.uk). 


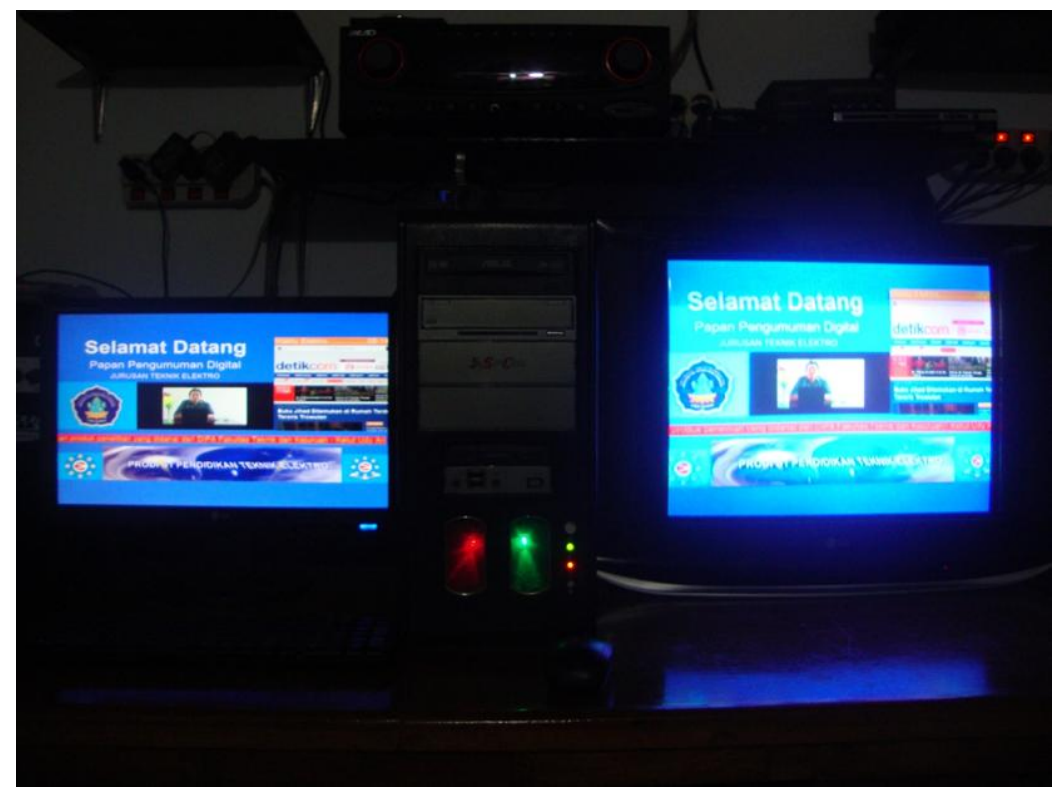

Gambar 4. Papan Pengumuman Digital pada PC Client dan TV Plasma

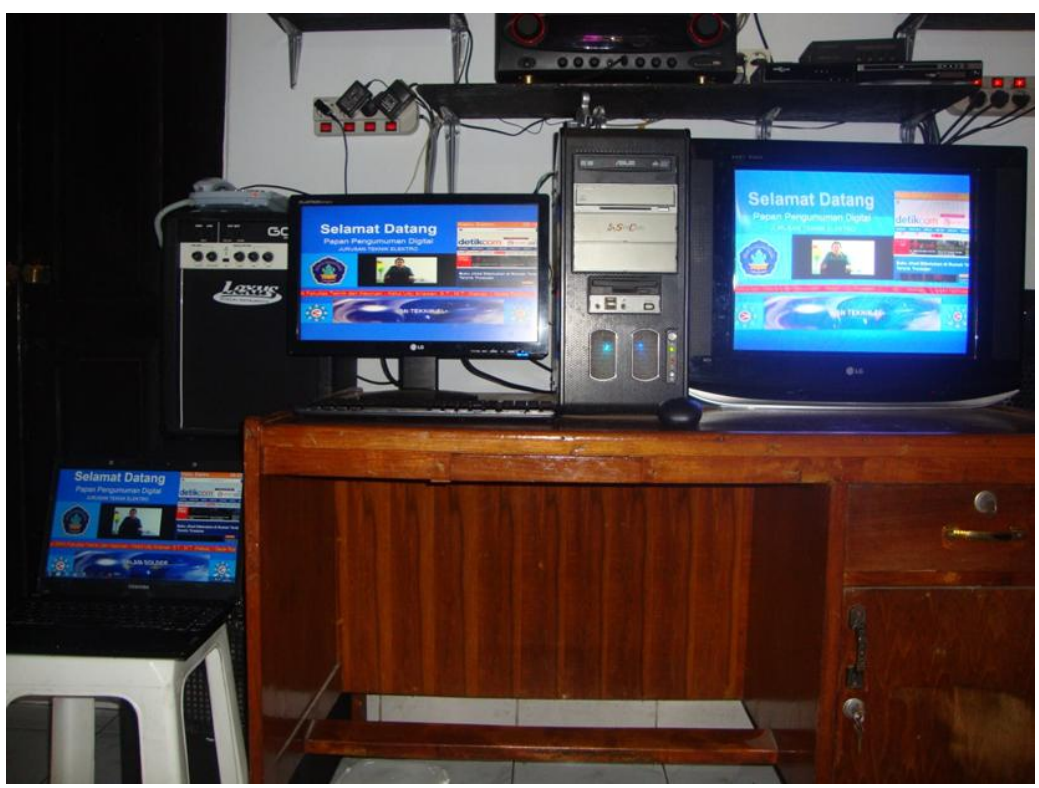

Gambar 5. Papan Pengumuman Digital pada PC Server, Client, dan TV Plasma

\section{b. Pembahasan}

\section{Pengujian Responsivitas (Delay)}

Pengujian ini diperoleh dari pengukuran waktu pengendalian dari PC Server ke PC Client, seberapa cepat respon PC Client yang terhubung dengan TV Plasma menampilkan perubahan tampilan desain konten yang dilakukan pada PC Server secara online.

Pada saat pengujian menggunakan stop watch yang tersedia di dalam aplikasi smartphone sebagai pengukur waktu. Perubahan desain layout yang dilakukan di dalam 
XIBO CMS melalui PC Server waktu rata-rata yang diperoleh kurang dari 10 detik untuk ditampilkan pada layar TV Plasma yang terhubung dengan PC Client.

Tabel 1. Tabel Responsivitas

\begin{tabular}{|l|l|}
\hline Perubahan & Delay (detik) \\
\hline Teks Statis & 2 \\
\hline Teks Dinamis & 5 \\
\hline Video & 7 \\
\hline Gambar Statis & 1 \\
\hline Banner Dinamis & 1 \\
\hline Website Online & 9 \\
\hline
\end{tabular}

\section{Pengujian Fitur}

Data hasil pengujian fitur diperoleh dari kemampuan digital signage XIBO yang terhubung dengan PC Server menampilkan fitur-fitur yang dimilikinya, seperti menampilkan informasi berbasis teks statis, teks dinamis, gambar statis, gambar dinamis, banner dinamis, video, dan homepage sebuah website secara sempurna pada PC Client yang terhubung dengan TV Plasma.

a. Menampilkan Teks Statis, pada saat dilakukan pengujian digital signage XIBO ternyata mampu secara sempurna menampilkan teks statis.

b. Menampilkan Teks Dinamis, pada saat dilakukan pengujian digital signage XIBO hanya mampu menampilkan secara sempurna teks dinamis yang bergerak horizontal dan vertikal (marque), sedangkan untuk efek teks fade, scroll, flip, shuffle, dan tile tampilannya masih terkesan patah-patah bahkan ada yang sama sekali tidak bisa ditampilkan.

c. Menampilkan Gambar/Image Statis, pada saat dilakukan pengujian digital signage XIBO ternyata mampu secara sempurna menampilkan gambar/image statis yang berformat jpg, jpeg, png, dan bmp.

d. Menampilkan Gambar/Image Dinamis, pada saat dilakukan pengujian digital signage XIBO ternyata mampu secara sempurna menampilkan gambar/image dinamis yang berformat gif.

e. Menampilkan Banner Dinamis, pada saat dilakukan pengujian digital signage XIBO ternyata mampu secara sempurna menampilkan banner dinamis berformat swf (flash).

f. Menampilkan Video, pada saat dilakukan pengujian digital signage XIBO ternyata mampu secara sempurna menampilkan video yang berformat mp4 saja, sedangkan untuk format file video lain (wmv, avi, mpg, mpeg, dan webm) sama sekali tidak bisa ditampilkan dan kapasitas video dibatasi hanya sebesar $8 \mathrm{Mb}$. 
Menampilkan Web, pada saat dilakukan pengujian digital signage XIBO ternyata mampu secara sempurna menampilkan halaman depan sebuah website secara online, namun tampilannya terkesan lambat muncul tergantung dari kecepatan akses internet dan database.

\section{Pengujian Penjadwalan}

Data hasil pengujian penjadwalan diperoleh dari kemampuan jadwal tayang yang dimiliki digital signage XIBO agar bisa menampilkan desain konten yang telah dirancang pada hari-hari kerja dan jam kerja tertentu selama satu bulan, sehingga diluar waktu tersebut papan pengumuman digital yang dirancang ini tidak akan tampil.

Pada saat dilakukan pengujian, waktu yang digunakan untuk jadwal tayang ditentukan untuk waktu 1 jam, 1 hari, 1 minggu, dan 1 bulan. Penjadwalan sesuai dengan waktu yang ditentukan berdasarkan atas waktu yang terdapat di dalam komputer (jam komputer).

\section{PENUTUP}

Dari hasil penelitian yang telah dilakukan dalam proses pembuatan papan pengumuman digital ini, maka dapat ditarik beberapa kesimpulan bahwa:

a. Digital signage XIBO dapat dijadikan sebagai salah satu sarana dalam proses pembuatan papan pengumuman digital.

b. Fitur-fitur yang terdapat di dalam digital signage XIBO sangat bervariasi dan mudah untuk digunakan tapi masih ada beberapa fitur yang belum bisa digunakan secara sempurna, seperti efek teks dinamis, video, dan webpage.

c. Perubahan desain layout memerlukan waktu rata-rata kurang dari 10 detik untuk ditampilkan pada layar TV Plasma yang terhubung dengan PC Client.

d. Kemampuan jadwal tayang digital signage XIBO yang real time.

\section{DAFTAR PUSTAKA}

, 2015, About XIBO, http://xibo.org.uk/about/ (diakses tanggal 03 Juni 2015).

Aniendya Christianna, 2011, Desain Signage sebagai Solusi Pencemaran Visual, Jurusan Desain Komunikasi Visual, Fakultas Seni dan Desain, Universitas Kristen Petra, Surabaya.

Borg, W.R., Gall, M.D., 1989, Educational Research: An Introduction,Fifth Edition, New York: Longman. 
Bimo Sunarfri Hantono \& Guntur Dharma Putra, 2014, Analisis Unjuk Kerja Aplikasi Digital Signage Xibo Pada Single Board Computer Raspberry Pi, Seminar Nasional Teknologi Informasi dan Multimedia, ISSN: 2302-3805, STMIK AMIKOM, Yogyakarta.

B. Lukmanfiandy, dkk, 2013, Perancangan dan Implementasi Digital Signage Pada Media Informasi PT GMF AEROASIA Menggunakan XIBO, Jurusan Teknik Elektro dan Teknologi Informasi UGM, Yogyakarta.

Dedy Rahman Wijaya, 2013, Pengembangan Layanan Digital Signage untuk Penyebaran Informasi Akademik di Politeknik Telkom, Digital Information \& Systems Conference, ISBN: 978-979-1194-11-2, Universitas Kristen Maranatha, Bandung.

Vencysisca Jeane Risamena, dkk, 2013, Penyisipan Konten Elektro News Menggunakan Xibo Digital Signage, Prosiding Conference on Smart-Green Technology in Electrical and Information Systems, Jurusan Teknik Elektro UNUD, Denpasar. 